\title{
Outcome of Macrosomic Infants at the University Hospital of the West Indies
}

\author{
C Richardson, H Trotman
}

\begin{abstract}
Objective: To determine the outcome of macrosomic infants at the University Hospital of the West Indies over a three-year period.

Methods: A retrospective, descriptive, case controlled study was carried out. Data were extracted from the maternal and neonatal medical records of 316 macrosomic infants (weighing $\geq 4000$ grams) and 316 controls (weighing 2500-3999 grams) delivered at the University Hospital of the West Indies. Descriptive analyses were performed comparing maternal and neonatal characteristics and outcomes between the two groups.

Results: The incidence of macrosomia at the University Hospital of the West Indies for the study period was 43.5 per 1000 deliveries. Fetal macrosomia was associated with an increased risk of an operative delivery, shoulder dystocia and maternal postpartum haemorrhage $(\mathrm{p}<0.05)$. Macrosomic babies were more likely to be male, experience respiratory distress at birth and require admission to the Neonatal Unit ( $\mathrm{p}<0.05)$.

Conclusion: Macrosomia contributes significantly to maternal and neonatal morbidity. There needs to be targeted, coordinated perinatal and neonatal measures if these morbidities are to be reduced.
\end{abstract}

Keywords: Fetal macrosomia, macrosomic infants

\section{Resultado de los Bebés Macrosómicos en el Hospital Universitario de West Indies \\ C Richardson, H Trotman}

\begin{abstract}
RESUMEN
Objetivo: Determinar la evolución clínica de los recién nacidos macrosómicos en el Hospital Universitario de West Indies en un periodo de tres años.

Métodos: Se realizó un estudio de casos y controles retrospectivo, descriptivo. Los datos se extrajeron de las historias clínicas maternas y neonatales de 316 bebés macrosómicos (peso $\geq 4000$ gramos) y 316 controles (peso 2500-3999 gramos) nacidos en el Hospital Universitario de West Indies. Se realizaron análisis descriptivos comparando las características maternas y neonatales con los resultados entre los dos grupos.

Resultados: La incidencia de la macrosomía en el Hospital Universitario de West Indies en el periodo de estudio fue 43.5 por 1000 partos. La macrosomía fetal estuvo asociado con un mayor riesgo de parto quirúrgico, distocia de hombros, y hemorragia materna postparto $(\mathrm{p}<0.05)$. Los bebés macrosómicos eran más propensos a ser varones, experimentar dificultades respiratorias en el nacimiento, y requerir ingreso en la Unidad Neonatal $(\mathrm{p}<0.05)$.
\end{abstract}

From: Department of Child and Adolescent Health, The University of the West Indies, Kingston 7, Jamaica, West Indies.
Correspondence: Dr H Trotman, Department of Child and Adolescent Health, The University of the West Indies, Kingston 7, Jamaica, West Indies. Email: helen.trotmanedwards@uwimona.edu.jm 
Conclusión: La macrosomía contribuye significativamente a la morbilidad materna y neonatal. Se hacen necesarias medidas perinatales y neonatales coordinadas y específicas, si se quiere reducir estas morbilidades.

Palabras claves: Macrosomía fetal, bebés macrosómicos

West Indian Med J 2017; 66 (2): 270

\section{INTRODUCTION}

Macrosomia is defined as birthweight greater than or equal to 4000 grams or greater than or equal to 4500 grams regardless of gestational age (1). The prevalence of fetal macrosomia is $0.5-15 \%$ dependent on the weight used (2).

Increased birthweight has been linked to an increased incidence of maternal and fetal complications. Studies have shown that women who deliver a macrosomic infant tend to have prolonged labour, are more likely to have an operative delivery and to experience post-partum haemorrhage $(1,2)$. Neonatal complications seen in macrosomic infants include stillbirth, perinatal asphyxia, mortality secondary to birth asphyxia, shoulder dystocia, birth injury and meconium aspiration syndrome $(1,3,4)$.

Studies done in the English-speaking Caribbean have mirrored international studies in their findings of neonatal complications of macrosomia. In Antigua and Barbuda, Martin et al found neonatal complications of macrosomia included low Apgar scores, respiratory distress, birth trauma, shoulder dystocia, admission to the Neonatal Unit and increased mortality in infants > 4500 grams (5). Roopnarinesingh et al in Trinidad and Tobago showed that neonatal complications included shoulder dystocia, low Apgar scores, meconium aspiration and respiratory distress (6).

Fetal macrosomia remains a difficult obstetric problem with significant maternal, perinatal and neonatal consequences. There has been no study to date in Jamaica that has identified neonatal complications of macrosomic infants. This study aimed to determine the outcome of these infants at the University Hospital of the West Indies (UHWI) over a three-year period.

\section{SUBJECTS AND METHODS}

This was a retrospective, descriptive, case controlled study to determine the outcome of macrosomic infants at the UHWI. For the purpose of this study, a birthweight of $\geq 4000$ grams was used to define macrosomia regardless of gestational age. All macrosomic infants, delivered at UHWI between January 1, 2007 and December
31,2009 , were entered into the study except those with chromosomal abnormalities or congenital anomalies. A normal birthweight infant (2500-3999 grams) born closest in time to the index case was used as the control.

\section{Data collection}

The subject population was identified from the labour ward $\log$ books, Neonatal Unit log books and the pathology stillbirth log book. Patients' dockets (both mothers' and neonates' dockets) were retrieved and data on maternal and neonatal demographics, maternal complications, neonatal complications and outcome were recorded using a data extraction sheet. All infants with chromosomal abnormalities or congenital anomalies were excluded.

The maternal outcome parameters investigated were prolonged second stage ( $>1$ hour regardless of parity) of labour, shoulder dystocia, mode of delivery, the need for instrumentation, postpartum haemorrhage and length of hospital stay. Postpartum haemorrhage was defined as blood loss $>500 \mathrm{mLs}$ for spontaneous vaginal deliveries (SVD) and $>1000 \mathrm{mLs}$ in operative deliveries. The neonatal characteristics examined were gender and birthweight. Neonatal outcome parameters examined included Apgar scores, level of resuscitation, trauma, hypoglycaemia (defined as blood glucose $<2.2 \mathrm{mmol} / \mathrm{dL}$ ), presence of meconium, respiratory distress at delivery, admission to the Neonatal Unit, hyperbilirubinaemia, hypoxic ischaemic encephalopathy, presence of cephalhaematoma and bruising and status at discharge from hospital (alive $v s$ dead). Trauma at delivery looked at clavicular and humeral fractures and brachial plexus injury (BPI).

These parameters were compared between the macrosomic population and the control group.

\section{Statistical analysis}

Descriptive analyses were performed. Differences between normal birthweight infants and macrosomic infants were determined using the Chi-square and the Student's $t$-test. Data were analysed using the Statistical 
Programme for Social Sciences version 17. Statistical significance was taken at $p<0.05$

The UHWI/UWI/Faculty of Medical Sciences Ethics Committee granted permission for the conduct of this study.

\section{RESULTS}

During the study period, 317 babies with a birthweight of $\geq 4000$ grams were delivered at the UHWI; one case was excluded because of the presence of congenital anomalies. There were 7279 deliveries in total giving a rate of 43.5 per 1000 deliveries for macrosomic infants.

The maternal age of women who delivered macrosomic infants ranged from 17-44 years with a mean \pm SD of $29.84 \pm 6.1$ years, $80(25 \%)$ of the women were of advanced maternal age (>35 years) and $84(27 \%)$ were multiparous. While in the control group, maternal age ranged from 15-46 years with a significantly younger mean \pm SD maternal age of $28.34 \pm 6.8$ years $p<0.05$; $21 \%$ of the mothers were of advanced maternal age and $19 \%$ were multiparous. Women who delivered macrosomic babies were more likely to be delivered by lower segment Caesarean section (LSCS), when delivered vaginally they were more likely to have the complication of shoulder dystocia and they were more likely to have postpartum haemorrhage $[p<0.05]$ (Table 1).

Fourteen per cent of women who delivered a macrosomic infant had a history of having a previous macrosomic infant. There was no statistically significant difference in prolongation of the second stage of labour, need for instrumentation, rate of emergency Caesarean section or length of hospital stay for mothers between the two groups.
There was a male preponderance $201(64 \%)$ in the macrosomic infants when compared to $161(51 \%)$ in the control infants $(p=0.001)$. The birthweights of the macrosomic population ranged from 4000 to 5100 grams with a mean \pm SD of $4219 \pm 207$ grams. The majority, of the cases, (89\%) fell within the range 4000-4499 grams. In total there were three babies who weighed $\geq 5000$ grams. The largest birthweight recorded was 5100 grams. All of the babies $\geq 5000$ grams were delivered operatively and required admission to the Neonatal Unit. All of their mothers had a history of previous macrosomia. In the control group, the birthweights ranged from 2500-3920 grams with a mean \pm SD of $3206 \pm 334$ grams. Table 2 illustrates the neonatal characteristics and outcome of the babies within the study population.

There was no statistically significant difference between both groups with regards to Apgar scores at one and five minutes and resuscitation requiring intermittent positive pressure ventilation. More macrosomic babies were found to have respiratory distress at birth 132 (47\%) and required admission to the Neonatal Unit $86(28 \%)$ than those in the control group 104 (33\%) and $27(9 \%)$, respectively, $(p<0.001$, Table 2$)$. Within the macrosomic group, the most prevalent diagnosis was that of an infant of a diabetic mother (34\%), while for the control group, to rule out sepsis (41\%) was the most common reason for admission. Macrosomia was the sole indication for admission in 11 cases. Of the babies who had glucose monitoring, in 225 macrosomic babies and 43 controls there was no statistically significant difference in hypoglycaemia between the groups $50(22 \%)$ and 12

Table 1: Maternal demographics of women who delivered macrosomic infants at the UHWI 2007-2009 versus their control group

\begin{tabular}{lccc}
\hline & $\begin{array}{c}\text { Macrosomic } \\
\text { group n (\%) }\end{array}$ & $\begin{array}{c}\text { Control group } \\
\mathbf{n}(\%)\end{array}$ & $\begin{array}{c}p \text {-value } \\
\text { (Chi-square) }\end{array}$ \\
\hline Prolonged second stage (>1 hour) & $4(3)$ & $9(4)$ & 0.36 \\
Previous macrosomia & $42(14)$ & $5(2)$ & $<0.001$ \\
Caesarean delivery & $156(49.4)$ & $93(29.4)$ & $<0.001$ \\
Emergency LSCS & $75(48)$ & $42(45)$ & 0.66 \\
Instrumentation & $2(0.7)$ & $1(0.3)$ & 0.478 \\
Shoulder dystocia† & $24(15)$ & $5(2)$ & $<0.001$ \\
Post-partum haemorrhage & $32(10.1)$ & $18(5.7)$ & 0.015 \\
Length of stay $>3$ days & $46(15)$ & $36(11)$ & 0.14 \\
\hline
\end{tabular}

$\dagger$ : Percentages based on vaginal deliveries; LSCS: lower segment Caesarean section 
Table 2: Neonatal characteristics of macrosomic infants at the UHWI 2007-2009 versus the control group

\begin{tabular}{lccc}
\hline & $\begin{array}{c}\text { Macrosomic group } \\
\mathbf{n}(\mathbf{\%})\end{array}$ & $\begin{array}{c}\text { Control group } \\
\mathbf{n}(\%)\end{array}$ & $\begin{array}{c}\boldsymbol{p} \text {-value } \\
\text { (Chi-square) }\end{array}$ \\
\hline Male gender & $201(64)$ & $161(51)$ & 0.001 \\
1 min Apgar $<7$ & $50(16)$ & $35(11)$ & 0.051 \\
5 min Apgar $<7$ & $9(3)$ & $4(1)$ & 0.131 \\
Resuscitation (IPPV) & $30(10)$ & $20(6)$ & 0.054 \\
Meconium at birth & $59(19)$ & $59(19)$ & 0.368 \\
Respiratory distress at birth & $132(42)$ & $104(33)$ & 0.001 \\
SCN admission & $86(27)$ & $27(9)$ & $<0.001$ \\
Jaundice & $125(40)$ & $138(44)$ & 0.419 \\
HIE & $3(0.9)$ & $1(0.3)$ & 0.283 \\
Cephalhaematoma & $4(1)$ & $4(1)$ & 0.591 \\
Bruising & $1(0.3)$ & $2(0.6)$ & 0.533 \\
Stillbirth & $3(0.9)$ & 0 & 0.124 \\
\hline
\end{tabular}

SCN: special care nursery; HIE: hypoxic ischaemic encephalopathy

(28\%), respectively. Within both groups, the majority of the admissions were immediately post-delivery (71\%) and the modal age of admission for both groups was $<1$ day.

All cases of trauma in the neonates were found within the macrosomic group and all were complicated by shoulder dystocia. There were four cases of fractures and one case of brachial plexus injury (BPI). All fractures that occurred were at the humerus. The single case of BPI was Erb's palsy and was associated with a fracture of the humerus.

There were four reported cases $(1 \%)$ each of cephalhaematoma in both the macrosomic and control groups. Bruising was identified in one case in the macrosomic group and two cases in the control group. There was no statistically significant difference in the occurrence of meconium at birth, hypoglycaemia, jaundice and hypoxic ischaemic encephalopathy between the two groups (Table 2).

The mean \pm SD length of stay, for the babies was found to be $5.2 \pm 4.7$ days in the macrosomic group and $5.3 \pm 4.0$ days in the control group, with a modal length of stay of four days for each. There were two babies who required readmission to the Neonatal Unit. Both babies were from the macrosomic group, were infants of a diabetic mother and had hyperbilirubinaemia.

There were three stillbirths and all were within the macrosomic group. Two of these were delivered via LSCS because of fetal jeopardy. The mother of the third stillbirth delivered vaginally and experienced shoulder dystocia requiring instrumental intervention. There were no neonatal deaths in either group.

\section{DISCUSSION}

It has been shown that there is an increase in operative deliveries of macrosomic infants (7-9). Emergency operative deliveries have been reported to be more common than elective deliveries. Our study also revealed this increased incidence of operative over vaginal deliveries. However, there was no significant difference with regards to the type of operative delivery ie emergency $v s$ elective. Most studies showed that the leading cause for LSCS is primarily related to dystocia (cephalopelvic disproportion and failure to progress). The main indication, in our study, for LSCS within the macrosomic group, was presumed macrosomia (38\%). Dystocia as an indication for LSCS was only seen in $15 \%$. This finding, in our study, does parallel other studies which have shown that an antenatal diagnosis of macrosomia often results in an operative delivery (3).

We did not find a relationship between macrosomia and the need for instrumentation. This finding paralleled that of Zhang et al (2). This could be related to the increased incidence of operative deliveries for presumed macrosomia at our institution. Shoulder dystocia is thought to be the most serious complication of macrosomia. Its occurrence increases with increasing birthweight. The incidence of shoulder dystocia in our study was $15 \%$ of the vaginal deliveries, in the macrosomic group. Again this low incidence can be a reflection of the increased operative deliveries in women with fetal macrosomia at our institution.

We found postpartum haemorrhage ( $\mathrm{PPH})$ to be another complication associated with women who delivered macrosomic babies. However, unlike Lim et al who 
found eight-fold risk of PPH if the mother had an operative delivery (7), we found no association between PPH and mode of delivery.

In this study, we found that macrosomic babies were more likely to be male, have respiratory distress at birth, require admission to the Neonatal Unit and experience birth trauma. Macrosomic babies have a two to three-fold risk of hypoglycaemia, hyperbilirubinaemia, Neonatal Unit admission and hypoxia $(1,10)$. Hypoglycaemia and hyperbilirubinaemia did not prove to be significant associations in our study. The lack of an association of an increased incidence of hypoglycaemia in the macrosomic infants may speak to the effectiveness of the policy at our institution where all babies are put to the breast within one hour of life and macrosomic infants are subsequently fed every two hours once oral feeds are tolerated.

The babies within the macrosomic group did not require more extensive resuscitation when compared to the control group. This is in contrast to Ju et al who found a two-fold increase in resuscitation at birth for the macrosomic population (11). Asphyxia has been found to be the leading cause of death for macrosomic babies with those $>5000$ grams at the highest risk $(1,2)$. Asphyxia as well as low one and five minute Apgar scores were not found to be significant complications in our study and this could be due to the increased incidence of operative deliveries within the macrosomic group.

An increased risk of morbidity has been noted the higher the birthweight. This is most evident when the weight is $>4500$ grams. There is a two to three-fold increase in still birth and neonatal death rate once birthweight is 4500-4999 gram; it further increases to 5-13 times once birthweight is $>5000$ grams (2). We recorded only three stillbirths within this study and no neonatal deaths. These did not prove to be statistically significant. Being a retrospective study, data collection was limited by what data were recorded, in this study there may have been under-reporting of neonatal findings such as small cephalhaematomas particularly in the babies who were not admitted to the Neonatal Unit. There is the possibility that a few babies who may have developed complications post discharge may have sought private medical care, however, traditionally, this number is very minimal and so would not greatly affect study results. Babies within the control group would not have received routine glucose monitoring and so there is the possibility of underestimation of hypoglycaemia in this group.
Macrosomia confers a risk to both the mother and neonate in our population. We therefore need to identify women who are at high-risk of delivering a macrosomic infant as early in the pregnancy as possible and institute close monitoring. Excessive weight gain during pregnancy increases the risk of macrosomia, we therefore recommend ongoing dietary and nutritional advice and education on appropriate exercise. Abnormalities of glucose control increases the risk of macrosomia, we therefore recommend pre-pregnancy and pregnancy counselling of women who have diabetes to maintain appropriate glucose control prior to and during the pregnancy. Prompt identification of mothers who are at high-risk of poor glucose control eg those who are obese, for early screening and proper glucose monitoring and control throughout pregnancy. All neonates with birthweight $>$ $4000 \mathrm{~g}$ need to be closely monitored for possible complications such as birth trauma and respiratory distress.

\section{CONCLUSION}

Macrosomia confers a risk to both the mother and neonate in our population. There needs to be targeted, coordinated perinatal and neonatal measures if these morbidities are to be reduced.

\section{REFERENCES}

1. American College of Obstetricians and Gynaecologists (ACOG). Fetal Macrosomia. ACOG Practice bulletin No. 22 Washington, DC: ACOG 2000.

2. Zhang X, Decker A, Platt RW, Kramer MS. How big is too big? The perinatal consequences of foetal macrosomia. Am J of Obstet Gynecol 2008; 198: 517.e1-517.e6

3. Boulet SL, Salihu HM, Alexander GR. Mode of delivery and birth outcomes of macrosomic infants. J Obstet Gynaecol 2004; 24: 622-9.

4. Kamanu CI, Onwere S, Chigbu B, Aluka C, Okoro O, Obasi M. Fetal macrosomia in African women: a study of 249 cases. Arch Gynecol Obstet 2009; 279: 857-61.

5. Martin TC, Clarke A. A case control study of the perinatal complications associated with fetal macrosomia in Antigua and Barbuda. West Indian Med J 2003; 52: 231-4.

6. Roopnarinesingh S, Bassaw B, Bodoe L, Roopnarinesingh E. Perinatal implications for macrosomic babies. West Indian Med J 1991; 40: 89-92.

7. Lim JH, Tan BC, Jammal AE, Symonds EM. Delivery of macrosomic babies: management and outcomes of 330 cases. J Obstet Gynaecol 2002; 22: 370-4

8. Sadeh-Mestechkin D, Walfisch A, Shachar R, Shoham-Vardi I, Vardi H, Hallak M. Suspected macrosomia? Better not tell. Arch Gynecol Obstet 2008; 278: 225-30.

9. Koyanagi A, Zhang J, Dagvadorj A, Hirayama F, Shibuya K, Souza JP et al. Macrosomia in 23 developing countries: an analysis of a multicountry, facility-based, cross-sectional survey. Lancet 2013; 9: 476-83. 
10. Hedderson MM, Weiss NS, Sacks DA, Pettitt DJ, Selby JV, Quesenberry CP et al. Pregnancy weight gain and risk of neonatal complications: macrosomia, hypoglycaemia and hyperbilirubinemia. Obstet Gynecol 2006; 108: 1153-61.
11. Ju H, Chadha Y, Donovan T, O'Rourke P. Fetal macrosomia and pregnancy outcomes. Aust N Z J Obstet Gynaecol. 2009; 49: 504-9. 